Челябинский государственный университет,

129, ул. Братьев Кашириных, г. Челябинск, 454001, Россия,

Южно-Уральский государственный гуманитарно-педагогический университет, 69, пр. Ленина, г. Челябинск, 454080, Россия

E-mail: Svetlana_kush@mail.ru

ORCID iD: 0000-0003-4447-4606

Статья поступила 01 февраля 2021 г.; принята 21 марта 2021 г.; опубликована 31 марта 2021 г.

Аннотация. Статья посвящена изучению фреймирования представлений о законе и порядке как социальной проблеме. Актуальность определяется обращением к механизмам медийной репрезентации общественного неблагополучия. Конструирование значений о правонарушениях исследуется в аспекте фреймовых структур. Контекстуальный, дискурсивный и фреймовый анализ применяются для выявления того, как диагностируется проблема, какому социальному актору приписывается ответственность за её решение и как это оценивается в британском местном издании «The Nottingham Post». Доказывается, что макрофрейм ЗАКОН и ПОРЯДОК конституируют фреймы и слоты, фокусирующие внимание на опасных деяниях, к которым относятся преступления, совершаемые с использованием холодного оружия, на сексуальной почве, по причине ненависти, связанные с употреблением наркотиков и алкоголя, незаконная деятельность и неприемлемое социальное поведение. Полученные результаты представляют интерес для филологической урбанистики, медиалингвистики, дискурсологии.

Ключевые слова: Город; Медиаязык города; Медийная репрезентация; Социальные проблемы; Фреймирование; Закон и порядок; Медиакоммуникация; СМИ

Благодарности. Исследование выполнено при финансовой поддержке РФФИ и Челябинской области в рамках научного проекта № 20-412-740004 («Медийная репрезентация социальных проблем городской среды: конструирование систем значений»).

Информация для цитирования: Кушнерук С. Л. Закон и порядок как социальная проблема в дискурсе городского издания // Научный результат. Вопросы теоретической и прикладной лингвистики. 2021. Т.7, № 1. С. 33-48. DOI: $10.18413 / 2313-8912-2021-7-1-0-4$ 


\title{
Svetlana L. Kushneruk (D) Law and order as social problem in the discourse of city paper
}

\author{
Chelyabinsk State University, \\ 129 Brothers Kashirin St., Chelyabinsk, 454001, Russia, \\ South Ural State Humanitarian Pedagogical University, \\ 69 Lenin St., Chelyabinsk, 454080, Russia \\ E-mail: Svetlana_kush@mail.ru \\ ORCID iD: 0000-0003-4447-4606
}

Received 01 February 2021; accepted 21 March 2021; published 31 March 2021

\begin{abstract}
The article focuses on framing law and order as an urban problem. The research investigates the mechanisms of discourse representation of the social ill-being in the local media. Meaning construction is studied in the aspect of frame structures of varying conceptual complexity. Contextual, cognitive-discursive and frame analyses are employed to identify how a problem is diagnosed, which social actor is assigned responsibility, and how it is evaluated in the British media The Nottingham Post. The notion of LAW and ORDER macroframe is introduced to denote a complex cognitive construct that directs readers' attention to the theme within which the life of the city is discussed. It is argued that LAW and ORDER macroframe consists of frames and slots that focus on different offences. Those include knife crimes, sexual offences, drug offences, hate crime, drink driving, illegal activity, anti-social behaviour. The results of the research might present interest for urban studies, media linguistics, and discourse studies.
\end{abstract}

Keywords: City; Media language of the city; Media representation; Social problems; Framing; Law and order; Media communication; Mass media

Acknowledgments. The research was funded by RFBR and Chelyabinsk Region, project number 20-412-740004 ("Media representation of social urban issues : construction of meaning systems").

How to cite: Kushneruk, S. L. (2021). Law and order as social problem in the discourse of city paper. Research Result. Theoretical and Applied Linguistics, V.7 (1), 33-48, DOI: 10.18413/2313-8912-2021-7-1-0-4

1. Актуальность исследования социальных проблем города в медиалингвистическом аспекте

Проблемы городов всё чаще оказываются в поле зрения специалистов из разных областей гуманитарного знания культурологии, социологии, социальной политики (Воронина, 2008; Копцева, 2015; Кораблёва, 2017; Современные городские 2020; Столбов, 2019). Обширно представлены исследования языка города в отечественной русистике (Ларин, 1977; Крысин, 2003), социальной лингвистике (Исмагилова, 2009; Исмагилова, Майорова 2019;
Китайгородская, Розанова 2010; Красильникова, 1990; Эмер, 2014; Юнаковская, 2011), диалектологии (Елистратов, 1994; Ерофеева, 2017; Химик, 2000), филологической урбанистике (Андреев, 2012; Ермакова, 2011; Искужина, Салихова, 2013; Исхакова, 2001; Исмагилова, 2009; Колесов, 2005; Прокуровская, 1996; Шкатова, 1988), ономастике (Бутеев, 2012; Вайрах, 2019; Горланова, 2006; Грибанова, Гарико, 2011).

Указанные публикации главным образом посвящены изучению используемой горожанами речи как известного жителям 
«кода», а также разнотипных текстов городской среды (вывески, афиши, рекламные произведения, граффити) в рамках лингвистического градоведения (Теоретические ... 1998). С этих позиций семиотика урбанистического пространства включает три аспекта: 1) стилевое многообразие города; 2) диалог города и горожанина; 3) социокультурное исследование городской эпиграфики (Подберезкина, 1998: 22).

Обобщённым объектом анализа в названных работах является «язык города». Термин нельзя считать строгим с теоретической точки зрения, поскольку в качестве иллюстраций приводятся факты рефлексии жителей, отражённой в названиях магазинов, организаций, фирм, улиц, других знаках городского ономастикона, наряду с заголовками газетных статей и рекламными текстами (Михайлова, 2019).

Приходится признать, что в настоящее время практически отсутствуют комплексные исследования медиаязыка города в аспекте конструирования систем значений, формирующих представления об острых социальных проблемах. Вместе с тем местные медиа создают урбанистическую панораму, в которой много места отводится вопросам, требующим внимания со стороны властей. Сказанное определяет актуальность предпринятого исследования, в фокусе которого закон и порядок как одна из сложнейших социальных проблем (Kerbo, Coleman, 2006), отражённая в медиакартине, ориентированной на горожан.

В настоящей статье представлена часть результатов коллективного проекта, который посвящён изучению медийных репрезентаций социальных проблем городской среды крупного в России города Челябинска и его двух побратимов - графства Ноттингемшир в Великобритании и Коламбии в США [https://cheladmin.ru/]. Для его реализации привлекается зарубежный опыт.

Целью настоящей работы является систематизация фреймовых структур, создающих фрагмент городской медиакартины и формирующих представления о нарушениях закона и особенностях освещения данной разновидности социального неблагополучия в локальной британской прессе.

\section{2. Дискурсивный мир города как} репрезентационная структура: постановка проблемы

Методология исследования основана на сосуществующих подходах, ведущими из которых являются социокогнитивная теория дискурса (Van Dijk, 2016), теория дискурсивных картин мира (Картины русского мира, 2011), теория когнитивнодискурсивного миромоделирования (Кушнерук, 2018), теория текстовых миров (Огнева, 2009, 2019), а также теория фреймирования (Entman, 1993; Gamson, Modigliani, 1987; Van Gorp, 2005).

Проблемы городской среды опосредованы медиадискурсом. В ракурсе проводимого анализа представления о социальных проблемах города складываются на основе обращения к репрезентационной структуре, объективируемой в медиа средствами языка, которая имеет ментальную природу и зависит от контекста (Gavins, Lahey, 2016). Мы обосновываем понятие «дискурсивный мир города» и трактуем его как репрезентационную структуру, которая соотносится с процессами и результатами представления города в СМИ и реконструируется на основе тематически объединённой совокупности текстов.

Когнитивными опорами дискурсивного мира города являются макрофреймы, содержащие упорядоченные объёмы информации. Они определяются как концептуально-сложные конструкты, направляющие внимание аудитории на тематические области, в пределах которых обсуждается городская жизнь.

В основе такого подхода лежат положения теории когнитивнодискурсивного миромоделирования (основные публикации автора: http://discourseworld.ru/) и теория фреймирования, зарекомендовавшая себя как надёжный методологический инструмент для анализа того, как средства массовой 
коммуникации конструируют системы значений.

В медиадискурсивных исследованиях фрейм рассматривается как принцип отбора, выделения и представления информации либо как способ написания или создания сообщения, а также как инструмент, используя который СМИ «упаковывают» информацию для аудитории (Brüggemann, 2014; Cacciatore et al., 2016; D'Angelo, 2010; Ireri et al. 2019; Matusitz, 2013; Reese, 2007; Tewksbury, Scheufele 2009).

Фрейм является результатом фреймирования, суть которого «заключается в калибровке - увеличении или уменьшении элементов изображаемой реальности, чтобы сделать их более или менее заметными» (Entman, 1991: 9). За основу принимается следующее определение: «Фреймировать - значит выбрать некоторые аспекты воспринимаемой реальности и сделать их более заметными в тексте таким образом, чтобы это способствовало определению проблемы, причинно-следственной интерпретации, моральной оценке и/или рекомендациям. Обычно фреймы диагностируют, оценивают и предписывают» (Entman, 1993: 53). В названной трактовке утверждается идея сознательного выбора средств в представлении новостного сюжета.

Журналисты акцентируют значимость событий или явлений при помощи лексики, устойчивых выражений, повторов, визуальных элементов, культурно маркированных символов, что определяет общественное мнение (De Vreese, 2005; Godefroidt et al., 2016; Tuchman, 1978). Фреймы могут актуализироваться посредством ключевых слов, метафор, понятий, символов, визуальных образов, которые выделены в новостном нарративе (Entman, 1991: 7).

Bсе фреймовые структуры представляют собой когнитивные конструкты, в виде которых организованы знания о городской жизни и её фрагментах. Принципиально, что они различаются по концептуальному объёму. Это позволяет выде- лять макрофреймы, фреймы, субфреймы и слоты. Система фреймов и субфреймов конституирует макрофрейм. Как будет показано, набор слотов свидетельствует об особенностях фокусировки фреймов, об особой значимости отдельных аспектов в освещаемом журналистами фрагменте социального опыта.

\section{3. Когнитивно-дискурсивный под- ход: материалы и методы исследования}

Материалом для исследования послужил корпус, включающий 658 текстов, отобранных по ключевому слову «сіtу» из британского ежедневного таблоида «Тhe Nottingham Post» за 2010-2017 гг. Газета позиционируется как «пользующийся доверием местный новостной бренд», стремящийся к точному и своевременному представлению информации [https://www.nottinghampost.com/about-us/]. В созданной коллекции затем были проанализированы 262 контекста, релевантные цели исследования.

В качестве макропарадигмального избран когнитивно-дискурсивный подход, предполагающий синтез ментальных, коммуникативных и языковых факторов. В такой перспективе возможно комбинировать методики и приёмы для моделирования ментальных структур дискурсивного типа, которые формируют восприятие городской среды. Применяются контекстуальный, корпусный, дискурсивный и фреймовый анализы.

Контекстуальный анализ осуществляется для изучения синтагматических отношений выделенных лексических единиц. Корпусный подход трактуется в узком смысле как использование корпусного инструментария для «воссоздания» репрезентационной структуры по текстовым данным. Дискурсивный анализ применяется для установления особенностей фреймирования проблем городской среды с учётом контекста и носит индуктивный характер (Не, 2010: 88).

В отечественной и зарубежной лингвистике активно поддерживается мнение о том, что изучение дискурса может оказать- 
ся ещё более продуктивным, если когнитивные аспекты интегрировать с контекстуальными - коммуникативными и социальными (Van Dijk, 2016; Wodak, 2006; Болдырев, 2020; Будаев, Чудинов, 2020; Интерпретация... 2017]. Представляется, что применение названных методов способствует более глубокому пониманию дискурсивных механизмов «портретирования» городского неблагополучия, связанного с нарушениями закона. Подчеркнём особую значимость фреймового анализа, позволяющего обнаружить интерпретационные схемы, при помощи которых журналисты диагностируют проблему, оценивают её и дают рекомендации относительно возможных путей решения.

Определение того, каким образом фреймируются представления о законе и порядке города, производится на основе анализа лексико-семантических средств, синтаксических структур и пресуппозиции. Для оценки характера фреймирования ставятся следующие вопросы:
- как диагностируется / разъясняется проблема, при помощи каких средств и в каких контекстах;

- какому социальному актору приписывается ответственность за её решение;

- что сказано о действиях / решениях социального актора и как они квалифицируются в текстах СМИ.

В дискурсивном мире города выделяются несколько макрофреймов, которые являются его опорными когнитивноконструктивными звеньями. В настоящей работе, однако, автор ограничивается анализом макрофрейма ЗАКОН И ПОРЯДОК.

4. ЗАКОН И ПОРЯДОК в дискурсивном мире города: результаты и дискуссия

Макрофрейм ЗАКОН И ПОРЯДОК насыщает локальное медиапространство представлениями о нарушениях закона, характере преступлений, действиях уполномоченных органов и городской администрации. Соответствующий фрагмент дискурсивного мира города схематично представлен на рисунке.

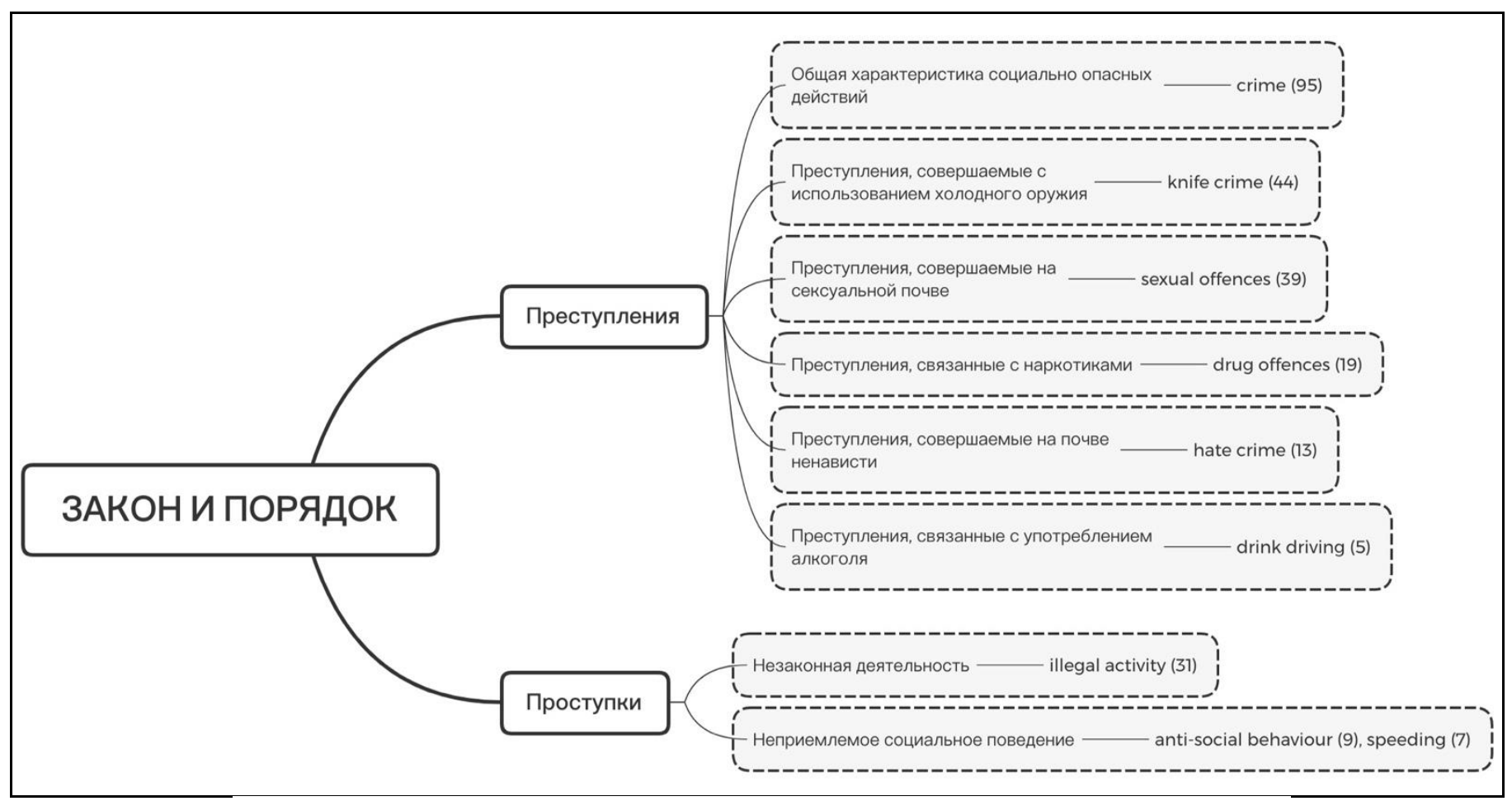

Рис. Фреймы и слоты как элементы макрофрейма ЗАКОН И ПОРЯДОК

Fig. Frames and slots as constituents of macroframe LAW AND ORDER 
Макрофрейм ЗАКОН И ПОРЯДОК включает два фрейма - Преступления и Проступки, которые распадаются на слоты (напротив каждого указаны базовые репрезентанты и количество употреблений).

\section{Фрейм Преступления включает} шесть слотов.

Слот «Общая характеристика социально опасных действий» диагностирует проблему, заключающуюся в том, что Ноттингем приобрёл репутацию города, где регулярно осуществляется преступная деятельность с применением оружия, в том числе в отношении студентов (a spate of shootings had given Nottingham a reputation for gun crime, 260 incidents of violent crime in Nottingham against students).

Активация фрейма осуществляется за счёт статистических данных. Ср.: Total recorded crime in Nottinghamshire has risen by six percent in the same time frame - double the average. (21.01.16). [Общее количество зарегистрированных преступлений в Ноттингемшире выросло на шесть процентов за тот же период времени - вдвое больше, чем в среднем].

Контекстуальный анализ лексемы crime даёт представления о нескольких социальных акторах, имеющих отношение к совершению преступлений, - преступниках, жертвах и полиции. Преступники осуществляют противозаконные действия (crime was carried out, killers involved in the crime), демонстрируют жестокость, в том числе в состоянии алкогольного опьянения (violent crime, violent crime involving alcohol), в отношении неквалифицированных жертв (victims of crime).

Действия полиции как социального актора оцениваются положительно. Подчёркивается, что полицейские выполняют профессиональный долг, непрерывно отслеживают ситуацию в городе (dealing with crime, tackling violent crime), рассматривают частные случаи (selling of illegal tobacco is a crime), выявляют модели преступлений (pattern of crime), проводят расследования (crime scene investigation), бе- рут под контроль преступления с применением оружия (got a grip on gun crime), стараются обнаружить причины общественного характера, которые приводят к противозаконным деяниям (address the underlying issues in society which lead people to commit certain types of crime), ведут активную борьбу с незаконной деятельностью в молодёжной сфере (fighting youth crime), чтобы сократить общий уровень преступности (reduce crime in Nottinghamshire's communities), упредить нарушения закона (prevent crime) и отвлечь внимание молодёжи от деструктивной деятельности (guide young people away from crime).

\section{Субфрейм Виды преступлений.}

Слот «Преступления, совершаемые с использованием холодного оружия" фокусирует внимание на том, что в преступных целях активно используются ножи, клинки и подобные средства хозяйственно-бытового назначения (Nottingham's knife crime problem, city's knife crime problem, more incidents of knife crime are being reported, knife incidents, knife injuries).

Разъяснение проблемы осуществляется через апелляцию к авторитету - мнению окружного судьи. Ср.: District Judge Leo Pyle told Nottingham Magistrate's Court: "Knife possession has to stop - it causes tragedy. Every knife is a potential danger. Carrying knives is a scourge in this city and will not be tolerated by the courts» (14.06.16). [В городском суде Ноттингема окружной судья Лео Пайл заявил: «Нужно запретить хранение холодного оружия это приводит к трагедии. Каждый нож потенциальная опасность. Ношение ножа является бичом в этом городе и не будет допущено судом»].

Метафора «scourge» (рус. - бич, беда, кара), значение которой представлено семами «бедствие», «страдания людей», является риторическим средством привлечения внимания к существующей проблеме, вскрывает дополнительные стороны явления, влекущие негативные последствия для жителей. 
Обострение социальной ситуации связано с тем, что ношение холодного оружия становится обычным делом, особенно среди молодёжи. Ср.: Lot of them are young people in the 15 to 25 demographic. Carrying a knife is becoming normal for a number of people and if you carry a knife you are more likely to use it. (08.05.17). [Многие из них молодые люди в возрасте от 15 до 25 лет. Ношение ножа становится нормой, но если человек имеет при себе нож, он с большей вероятностью будет его использовать.].

Жители как социальные акторы находятся под ударом (affected by knife crime, victims of knife crime, fatal stabbing of a teenager), многие из них не отдают отчёт в существующей опасности (some people are clearly not taking knife crime seriously).

Ответственность за решение проблемы возложена на полицию (resolve the issue around knife crime, tackle knife crime). Cp.: Nottinghamshire Police has told the Post it takes knife crime "very seriously» and has a group of officers focusing all their efforts. (29.06.16). [Полиция Ноттингемшира заявила газете, что относится к преступлениям с использованием холодного оружия «очень серьёзно», имеется группа офицеров, прикладывающих все силы для их устранения].

Позитивнооценочные смыслы, связанные с действиями полиции, актуализируются благодаря прямой цитате. Уполномоченное лицо констатирует «многогранность» стратегии работы с такого рода преступлениями. Подчёркивается связь работы полиции с органами местной власти. Ср.: «Our dedicated knife crime team works proactively in partnership with local authorities and other teams within the force» (29.06.17). [Наш спецотдел по борьбе с преступлениями с использованием холодного оружия активно работает в партнёрстве с местными властями и другими отделами полиции].

Прогностический характер фрейма позволяет фокусировать внимание на будущих действиях, направленных на иско- ренение проблемы. Ср.: Our proactive and preventative activity around knife crime will continue. (05.07.17) [Наша упреждающая профилактическая деятельность по борьбе с преступлениями с применением холодного оружия будет продолжаться.].

Слот «Преступления, совершаемые на сексуальной почве». Фокусировка на данной разновидности преступлений осуществляется благодаря выбору лексикосемантических средств (child sexual exploitation, child sexual abuse in Nottinghamshire, child sex abuse inquiry, prevention of child sexual abuse). Устанавливается, что эти преступления чаще всего совершаются в отношении детей. Сp. заголовок: «15 children are currently at risk of sexual exploitation in Nottingham» (22.12.15) [В настоящее время в Ноттингеме риску сексуальной эксплуатации подвержены 15 детей].

Вскрывается проблема сексуального насилия и эксплуатации несовершеннолетних. Ср.: A man who claimed he was repeatedly made to watch his sister being raped by their foster father has applied to give evidence to an inquiry looking into historical child sexual abuse in Nottinghamshire. (11.05.17) [Мужчина, заявивший, что его много раз принуждали смотреть, как его сестру насилует приёмный отец, подал заявление о даче показаний в рамках расследования исторически громкого сексуального насилия над детьми в Ноттингемшире].

Ответственность за решение этих проблем возложена на полицию. Дескриптивный аспект освещения проявляется в констатации приверженности профессионалов своему делу. Вместе с тем подчёркивается участие властей города в решении острой проблемы. Cp.: Councillor David Mellen, said: "Keeping our children safe will always be a high priority for Nottingham City Council and we remain committed to working with our local partners to raise awareness of child sexual exploitation». (31.08.17) [Советник Дэвид Меллен сказал: «Обеспечение безопасности наших детей всегда будет высоким приоритетом Нот- 
тингемского городского совета, и мы попрежнему привержены работе с нашими местными партнёрами по повышению осведомлённости о сексуальной эксплуатации детей»].

Для положительной оценки действий городского совета также приводится реакция других общественных организаций. Так, представитель благотворительного фонда высказывается в поддержку данной инициативы. Ср.: "We are delighted that Nottingham City Council is involved in this because at the minute there is a shortage in provision in this area. One third of sexual offences on children are by other young people and we want to address this issue». (22.12.15) [Мы очень рады, что городской совет Ноттингема в этом участвует, потому что в настоящее время ощущается нехватка соответствующих мер. Треть преступлений на сексуальной почве в отношении детей совершается молодыми людьми, и мы хотим решить эту проблему].

Слот "Преступления, связанные с наркотиками" даёт понимание того, что в городе растёт число преступлений, совершаемых в состоянии наркотического опьянения, а также в связи с распространением наркотических веществ (an increase in the use of the drug on the streets of Nottingham, illegal drugs, drug use, drug addiction).

Привлечение внимание к проблеме во многих случаях осуществляется в заголовках газет: «Spike in number of 'zombied' drug users in city centre over weekend» (01.08.17) [Всплеск числа наркоманов «под кайфом» в центре города в минувшие выходные]. Многозначное слово spike включает семы «внезапный резкий скачок», а также функционально-стилистическую сему «шприц для подкожных инъекций», актуализируемую в сленге [https://www.merriam-

webster.com/dictionary/spike]. Ко-активация сем создаёт основу для метафорической репрезентации проблемы через фокусировку на состоянии людей, принимающих наркотики, и её усугубления.
Обобщённо ситуация в городе представлена следующим образом: совершаются преступления в состоянии наркотического опьянения (driven by this drug, affected by the drug), орудуют группировки, занимающиеся наркотиками (drug gangs), которые продают крэк и героин на улицах (selling crack and heroin on Nottingham's streets), подчёркивается высокий спрос на наркотики в городе (high demand for crack and heroin in Nottingham). К числу самых популярных веществ относятся спайс и мамба (smoking Spice and Mamba, availability of Spice/Mamba, to smoke the mamba), регистрируются случаи смерти в результате их употребления (the city's first Black Mamba related death).

Высокая степень опасности такого рода преступлений усиливается благодаря апелляции к мнениям авторитетных социальных акторов с большим профессиональным опытом, например врачей скорой помощи. Cp.: Wendy Hazard, EMAS ambulance operations manager for Nottinghamshire, who has worked for the NHS for 23 years, told the Post: "Nottingham has a problem and has the potential to being an increasing problem». [Венди Хазард, менеджер скорой помощи в Ноттингемшире, которая работала в системе здравоохранения 23 года, заявила газете «The Post»: «У Ноттингема есть проблема, и потенциально она может усугубиться»].

Разъяснение проблемы также обеспечивается через устрашение - благодаря описанию последствий влияния наркотических веществ на здоровье человека: появление галлюцинаций, развитие паранойи и панических атак. Ср.: Spice and Mamba, which can be swallowed or smoked, are associated with hallucinations, paranoia and panic attacks, and are similar to cannabis - but far more potent and dangerous. (01.08.17). [Спайс и Мамба, которые можно глотать или курить, порождают галлюцинации, паранойю и панические атаки, они похожи на каннабис, но являются гораздо более сильнодействующими и опасными]. 
Причины проблемы вскрываются через ссылку на мнение полиции. Компетентный орган связывает рост такого рода преступлений с дешевизной наркотиков. $\mathrm{Cp}$ : Nottinghamshire Police says the city is seeing an increase due to the cheap cost of these drugs. [Полиция Ноттингемшира говорит, что город переживает рост из-за низкой стоимости этих наркотиков].

Вовлечённость городских властей в решение проблемы носит опосредованный характер и ограничивается ожиданиями относительно работы уполномоченных лиц. Cр.: Nottingham City Council also says its enforcement officers patrolling the streets are confronting the problem "more regularly». This is becoming an increasing problem for us and it's important that the police focus on issues such as crime such as burglary and other acquisitive crimes that are being driven by this drug. (01.08.17) [Городской совет Ноттингема также заявляет, что сотрудники правоохранительных органов, патрулирующие улицы, сталкиваются с этой проблемой «более регулярно». Это становится все более серьёзной проблемой для нас, и очень важно, чтобы полиция сосредоточилась на таких вопросах, как кража со взломом и другие преступления, связанные с присвоением имущества, которые совершаются под действием этого наркотика].

Слот «Преступления, совериаемые на почве ненависти» констатирует увеличивающееся число преступлений, совершаемых по причине ксенофобских настроений и неприязни (an increase in hate crime, 100 victims of hate crime, attitudes and experiences of hate crime in Nottingham).

Проблема диагностируется через апелляцию к мнению «жертвы» - студентки из Украины. Ср.: One victim of hate crime who attended the launch was Ukraineborn Sofia Ben, 19, a first year student at the University of Nottingham, says she has been told on numerous occasions not to speak in Russian in the city including from students at the university. She told the Post: "It was really degrading. I would consider it a hate crime because it is an attack on my identity".
(13.07.17). [Одной из присутствовавших на собрании жертв преступления на почве ненависти была уроженка Украины София Бен, 19-летняя студентка первого курса Ноттингемского университета. Она заявила, что к ней много раз обращались с просьбой не говорить по-русски в городе, в том числе студенты университета. В интервью газете «The Post» она сказала: «Это было действительно унизительно. Я расцениваю это как преступление на почве ненависти, потому что это нападки на мою идентичность»].

Для решения проблемы поддерживается инициатива проведения исследования причин ненависти, которое предпринимается группой заинтересованных горожан, объединивших сотню пострадавших. Ср: Nottingham Citizens brought together $\underline{100}$ victims of hate crime from all over the city at the launch of its research into hate in the city. (13.07.17). [Граждане Ноттингема собрали вместе 100 жертв преступлений, совершённых на почве ненависти, чтобы начать собственное исследование природы ненависти в городе].

Позиция городских властей представлена в связи с поддержкой данной работы со стороны представителей полиции и советника городского совета. Ср.: Police and Crime Commissioner Paddy Tipping, deputy chief constable Rachel Barber and the head of communities for Nottingham City Council, Councillor Toby Neal, pledged to support the research on hate crime in Nottingham (13.07.17) [Комиссар отдела полиции по борьбе с преступностью Пэдди Типпинг, заместитель главного констебля Рэйчел Барбер и глава общин городского совета советник Тоби Нил, обещали оказать поддержку изучению преступлений на почве ненависти в Ноттингеме.].

Слот "Преступления, связанные с употреблением алкоголя». Опасность для городских жителей представляют преступления, которые совершаются в состоянии алкогольного опьянения. Проблема актуализируется как в заголовках, так и в основном тексте публикаций. Ср.: «Who was 
caught drink-driving?» [Кого поймали за рулём в нетрезвом состоянии?].

Обсуждаются меры, принимаемые в отношении преступников. В этой связи задействован регулятивный аспект освещения, заостряющий внимание на наказаниях, вынесенных судом. Ср.: Magistrates in Nottingham have dealt with the latest drink drivers in the city. All the offenders below pleaded guilty and left court with a variety of punishments. (26.05.17) [Члены городского магистрата в Ноттингеме вынесли решения по делам нетрезвых водителей. Все нарушители признали себя виновными и вышли из зала суда с различными наказаниями]. В обязательном порядке демонстрируется реакция на совершённые преступления со стороны властей. Граждан убеждают в безопасности города, что важно для укрепления представлении о благополучии и способности администрации и полиции держать ситуацию под контролем.

Актуализируются прогностические смыслы, описывающие потенциальные действия полицейских. Cp.: Nottinghamshire Police will do all we can to reassure people about their safety locally. (04.06.17) [Полиция Ноттингемшира сделает все возможное, чтобы заверить людей в безопасности города].

Заверения в безопасности носят персуазивный характер, что имплицирует качество профессиональной деятельности полицейских. Ср.: Our enquiries are ongoing but we'd like to reassure the public that there's no cause for concern and Nottingham City Centre remains a safe place to live, work and socialise. (17.08.17) [Наши расследования продолжаются, но мы хотели бы заверить общественность, что нет никаких причин для беспокойства, и центр Ноттингема остаётся безопасным местом для жизни, работы и общения.].

Фрейм Проступки содержит два слота.

Слот «Незаконная деятельность» фокусирует внимание на том, что в графстве наблюдаются многочисленные прояв- ления нелегальной деятельности: несертифицированные водители (illegal drivers, illegal touts, hackney taxi drivers in the city), продажа нелегальных сигарет (selling of illegal cigarettes), продажа нелегального табака (selling of illegal tobacco), нелегальная торговля (illegal sales, illegal trade) и др.

Первая из названных актуализируется в заголовке: «More than 100 taxis operating illegally in Nottingham» (26.10.17) [B Ноттингеме более 100 такси работают нелегально].

Разъяснение проблемы в виде косвенной цитаты исходит от социального актора, призванного отстаивать мнения горожан, - представителя департамента защиты общественных интересов. Ср.: $M r$ Antcliff claimed taxis with licences from nearby councils such as Gedling, Rushcliffe and even some as far away as Wolverhampton, are illegally parking on city streets to pick up passengers. (26.10.17) [Г-н Антклифф заявил, что такси с лицензиями из близлежащих районов, таких как Джедлинг, Рашклифф, и некоторых удалённых, например Вулверхэмптон, незаконно паркуются на городских улицах, чтобы подхватывать пассажиров].

Острота проблемы подчёркивается апеллированием к мнению разных людей, однотипно реагирующих на социальную проблему. Регулярным средством активации фрейма являются прямые цитаты. Ср.: Jack Kushner, spokesperson for Brake, the road safety charity, agreed with this statement, saying: "We urge the government to make roads policing a national policing priority to prevent this selfish, illegal and dangerous behaviour behind the wheel»». (01.11.16) [Джек Кушнер, представитель благотворительной организации по безопасности дорожного движения Brake, coгласился с этим заявлением, заявив: «Мы настоятельно призываем правительство сделать охрану дорог национальным приоритетом полиции, чтобы предотвратить подобное эгоистичное, незаконное и опасное поведение за рулём»]. 
В решении данной проблемы активно участвует администрация. Ср.: We need to clear up the city. It is littered with illegal activity and people want to know they are getting into safe cabs. (26.10.17) [Нам нужно очистить город. Он погряз (букв. замусорен) в незаконной деятельности, и люди хотят быть уверены, что они садятся в безопасные такси]. Метафоры очищения замусоренного города, представленные глаголами «to clear uр» (убирать, делать уборку), «littered» (замусоренный), способствуют созданию яркого образа городской власти как санитара, наводящего порядок, и способствуют формированию лояльного отношения к инициативам городской администрации.

Слот «Неприемлемое социальное поведение» диагностирует проблему антисоциального поведения, которое причиняет неудобства и вызывает недовольство горожан (incidents of anti-social behavior, anti-social manner on our streets, address this anti-social behaviour).

Общественно неодобряемое поведение главным образом демонстрируют молодые люди - байкеры и студенты университета, а также любители скоростной езды. Закономерной является реакция представителей полиции. Прямая речь маркирует ответственность социального актора, убеждающего в исчерпывающем характере предпринимаемых для решения проблемы мер. Такие смыслы актуализируются благодаря семантике глагола «reassure». Это должно убедить читателей не сомневаться в правильности и своевременности предпринимаемых действий. Ср.: "I'd like to reassure the public that we are taking action to tackle this menace of quad bikes and motorbikes being used in an anti-social manner on our streets». (31.05.17) [Я хотел бы заверить общественность, что мы принимаем меры для борьбы с угрозой использования квадроциклов и мотоциклов в антиобщественным манере на наших улицах].

Нарушение скоростного режима также рассматривается как социально неприемлемое поведение, которое старается пресечь полиция. Сp.: Inspector Simon Blincow, of Nottinghamshire Police, said: "Officers carry out operations throughout the year to tackle drivers who flout the law by speeding, not wearing seatbelts, using mobile phones and drink / drug driving». (01.11.16) [Инспектор полиции Ноттингемшира Саймон Блинкоу сказал: «Офицеры проводят операции в течение всего года для борьбы с нарушающими закон водителями, которые не соблюдают скоростной режим, не пристёгиваются ремнями безопасности, используют мобильные телефоны во время движения и садятся за руль в состоянии алкогольного / наркотического опьянения»].

\section{5. Заключение}

Макрофрейм ЗАКОН И ПОРЯДОК представляет собой глубинномногоступенчатую когнитивную структуру, выступающую значимым элементом дискурсивного мира города. Её конституируют фреймы «Преступления» и «Проступки», имеющие разветвлённую слотовую организацию, которая отражает точечную фокусировку и диагностирует проблемные зоны городской среды. К ним относятся социально опасные действия, включающие преступления, совершаемые с использованием холодного оружия, на сексуальной почве, по причине ненависти, связанные с употреблением наркотиков и алкоголя. К разряду проступков относится деятельность, характеризуемая как незаконная, а также неприемлемое социальное поведение. На фоне актуализации макрофрейма в медийном дискурсе местной газеты «The Nottingham Post» выделяются три социальных актора, которые оказываются вовлечёнными в названные проблемы, - горожане, полиция, городские власти.

Фреймирование представлений о преступлениях и проступках, совершаемых в городе, сопряжено с приписыванием ответственности за происходящее сотрудникам правоохранительных органов. Их деятельность оценивается позитивно, чему способствует выбор лексико-семанти- 
ческих и синтаксических средств, а также пресуппозиция, включающая представления о профессиональном долге и миссии. Действия полиции представлены как агентивные, что на языковом уровне проявляется в преобладании акциональных глаголов, а также прямых и косвенных цитат, статистических данных, привлекаемых для освещения того, как решается обозначенная проблема компетентными уполномоченными.

Деятельность полицейских представлена в тесной связке с работой местных властей, свидетельством чего являются регулярные идентификации мнений и позиций представителей городского совета, высказываемых по каждому частому решению проблемы. Такое положение дел способствует созданию благоприятного видения городской администрации со стороны читателей.

Дискурсивный анализ того, каким образом средствами медиа языка британских местных газет складываются представления о противозаконной деятельности в графстве Ноттингемшир в Великобритании, способствует выяснению факторов, которые в большей мере стимулируют и/или препятствуют формированию привлекательной городской среды, а также координации многосторонних связей местных органов власти с партнёрами в других странах.

\section{Литература}

Андреев В. К. Город в номинациях и текстах (на материале молодёжных субкультур г. Пскова) // Вестник Орл. гос. ун-та. Сер.: Новые гуманит. исслед. Орел, 2012. № 2 (22). C. $125-128$.

Болдырев Н. Н. Когнитивный подход в лингвистике и смежных областях знания // Вопросы когнитивной лингвистики. 2020. № 2 . С. 5-25.

Будаев Э. В., Чудинов А. П. Политическая метафорология на современном этапе развития (2010-2019 гг.) // Вопросы когнитивной лингвистики. 2020. № 3. С. 56-70.
Бутеев Д. В. Под покровом имён: словарь неофициальных топонимов г. Смоленска. Смоленск: Маджента, 2012. 163 с.

Вайрах Ю. В. Эргоурбонимия города Иркутска: структурно-семантический и лингвокультурологический аспекты исследования: монография. М.: ИНФРА-М, 2019. 96 с.

Воронина Н. И. Города и люди: культурная идентичность: монография. Саранск, 2008. $100 \mathrm{c}$.

Горланова И. Б. Топонимия г. Костромы: Автореф. дис. ... канд. филол. наук. Ярославль. 2006. $20 \mathrm{c}$.

Грибанова Л. В., Гарико О. С. Диахронический и синхронический аспекты номинаций улиц г. Брянска // Проблемы взаимодействия славянских языков и культур в их истории и современном состоянии. Брянск, 2011. С. $86-95$.

Елистратов В. С. Словарь московского арго. М.: Русские словари, 1994. 702 с.

Ермакова О. П. Жизнь российского города в лексике 30-40-х годов XX века: Краткий толковый словарь ушедших и уходящих слов и значений. Москва: Флинта: Наука, 2011. 192 с.

Ерофеева Т. И. Речевой портрет провинциального города: учеб. пособие по спецкурсу. Москва: ФЛИНТА, 2017. 192 с.

Интерпретация мира в языке: коллективная монография. Тамбов, 2017. 450 с.

Искужина Н. Г., Салихова Э. А. Гетерогенное языковое пространство города: специфика речевого контактирования // Филологические науки: Вопросы теории и практики. 2013. № 3. С. 181-186.

Исмагилова Н. В. Язык города Уфы: функционирование различных подсистем русского языка в условиях дву- и многоязычия. Уфа: Хан, 2009. 184 с.

Исмагилова Н. В., Майорова О. А. Язык города как социолингвистическая проблема: перспективы изучения // Вестник Башкирского ун-та. 2019. № 4. Т. 24. С. 900-909.

Исхакова 3. А. Двуязычие в городах Татарстана (80-90-е гг.). Казань: Фикер, 2001. 192 c.

Картины русского мира: современный медиадискурс / Резанова 3. И. [и др.]. Томск: ИД СК-С, 2011. 288 с.

Китайгородская М. В., Розанова Н. Н. Языковое существование современного горожанина: на материале языка Москвы. М.: Языки славянских культур, 2010. 496 с. 
Колесов В. В. Язык города. М.: Едиториал УРСС, 2005. $192 \mathrm{c.}$

Копцева Н. П. Социокультурное пространство современного российского города (на материале анализа города Красноярска): монография / Копцева Н. П., Сертакова Е. А. Красноярск: СФУ, 2015. 128 с.

Кораблева Г. В. Социальное пространство современного города: монография / Кораблева Г. В., Меренкова А. В. Москва: Флинта, изд-во Урал. ун-та, 2017. 252 с.

Красильникова Е. В. О различных явлениях в языке жителей разных городов // Функционирование литературного языка в уральском городе. Свердловск: изд.-во УрГУ, 1990. C. 4-12.

Крысин Л. П. Проблема социальной и функциональной дифференциации в современной лингвистике // Современный русский язык: социальная и функциональная дифференциация. М., 2003.

Кушнерук С. Л. Развитие теории когнитивно-дискурсивного миромоделирования за рубежом и в России // Вопросы когнитивной лингвистики. 2018. № 4. С. 115-125. URL: www.discourseworld.ru (дата обращения 25.12.2020).

Ларин Б. А. О лингвистическом изучении города // История русского языка и общее языкознание. М., 1977. С. 175-189

Михайлова Ю. Медиадискурс современного города как поликультурный феномен // West-East. 2019. Vol. 2/2. № 1. C. 93-96.

Огнева Е. А. Когнитивное моделирование концептосферы художественного текста. Белгород: Изд-во БелГУ, 2009. 280 с.

Огнева Е. А. Концепты-доминанты как информативные конструкты текстовых миров. M., 2019. 190 c.

Подберезкина Л. 3. Лингвистическое градоведение // Теоретические и прикладные аспекты речевого общения. Вып. 6. Красноярск - Ачинск, 1998. С. 22-30.

Прокуровская Н. А. Город в зеркале своего языка: на языковом материале г. Ижевска. Ижевск: изд-во Удм. гос. ун- та, 1996. 228 с.

Современные городские исследования: монография / ред. Савченко И. А., Козлова Ю. В. Москва: ИНФРА-М, 2020. 97 с.

Столбов В. П. Социология городской среды: монография / Столбов В. П., Староста П. Ю. Москва: ИНФРА-М, 2019. 174 с.
Химик В. В. Поэтика низкого, или Просторечие как культурный феномен. СПб: изд-во СПб, 2000. 272 с.

Шкатова Л. А. Специфика городского общения // Живая речь уральского города. Свердловск, 1988. С. 19-28.

Эмер Ю. А. Пространственная модель города в фольклоре: к проблеме коллективной самоидентификации горожанина // Вестник Томского гос. ун-та. 2014. № 1 (13). С. 18-24.

Юнаковская А. А. «Язык города» как лингвистическая проблема // Вестник Омского ун-та. 2011. № 3. С. 193-197.

Boydstun A. E., Card D., Gross J. H., Resnik P., Smith N. A. Tracking the development of media frames within and across policy issues. Working Paper. 2014. Pp. 1-25.

Brüggemann M. Between frame setting and frame sending: How journalists contribute to news frames // Communication Theory. Vol. 24, № 1. 2014. Pp. 61-82.

Cacciatore M., Scheufele, D., Iyengar S. The End of Framing as We Know It ... and the Future of Media Effects // Mass Communication and Society. Vol. 19, № 1, 2016. Pp. 7-23.

D'Angelo P. 2010. Introduction: Doing News Framing Analysis. In Doing News Framing Analysis: Empirical and Theoretical Perspective I edited by P. D'Angelo, and J. Kuypers. New York: Routledge. 2010. Pp. 1-14.

De Vreese Claes. News framing: Theory and typology // Information Design Journal. Vol. 13, № 1, 2005. Pp. 51-62.

Entman R. M. Framing U.S. coverage of international news: Contrasts in narratives of the KAL and Iran air incidents // Journal of Communication. Vol. 41, № 4, 1991. Pp. 6-27.

Entman R. M. Framing: Toward clarification of a fractured paradigm // Journal of Communication. Vol. 43, № 4, 1993. Pp. 51-58.

Gamson William A., Modigliani Andre. The Changing Culture of Affirmative Action. In Research in Richard G. Braungart \& Margaret M. Braungart (eds.), Political Sociology, Greenwich: JAI Press. 1987. Pp. 37-177.

Godefroidt Amélie, Berbers Anna, d'Haenens Leen. What's in a frame? A comparative content analysis of American, British, French, and Russian news articles // The International Communication Gazette. Vol. 78, № 8. 2016. Pp. 777-801.

He M. An analysis of framing in British news media representations of China and the Chi- 
nese (Ph.D.). Loughborough University. 2010. URL: $\quad$ https://dspace.lboro.ac.uk/dspacejspui/bitstream/2134/8470/2/Miao's $\mathrm{PhD}$ thesis for binding.pdf (Accessed 25 December 2020).

Ireri Kioko, Chege Njoki, Kibarabara Joy, Onyalla Don Bosco. Frame Analysis: Newspaper Coverage of Kenya's Oil Exploration in the Post2012 Discovery Era // African Journalism Studies. Vol. 40, № 1. 2019. Pp. 34-50.

Gavins J., Lahey E. (eds). World Building: Discourse in the Mind. Bloomsbury. 2016. 296 p.

Kerbo H. R., Coleman J. W. Social Problems // Social Sciences. 2006. Pp. 362-369.

Matusitz J. Terrorism and Communication: A Critical Introduction. London: Sage. 2013. $520 \mathrm{p}$.

Reese S. D. The framing project: A bridging model for media research revisited // Journal of Communication. Vol. 57, № 1. 2007. Pp. 148-154.

Tewksbury D. H., Scheufele D. A. News Framing Theory and Research. In Jennings Bryant \& Oliver Mary Beth (eds.), Media Effects: Advances in Theory and Research, Hillsdale: Erlbaum. 2009. Pp. 17-33.

Tuchman G. Making news. New York: Free Press. 1987. 244 p.

Van Dijk T. Sociocognitive Discourse Studies // Richardson J., Flowerdew J. (eds). Handbook of Discourse Analysis. Routledge. 2016.

URL: http://www.discourses.org/OldArticles/Sociocogn itive\%20Discourse\%20Studies.pdf_(Accessed 25 December 2020).

Van Gorp B. Where is the frame? Victims and Intruders in the Belgian press coverage of the asylum issue // European Journal of Communication. Vol. 20, № 4. Pp. 2005. 484-507.

Wodak R. Mediation between discourse and society: assessing cognitive approaches in CDA. // Discourse Studies. № 8 (1). 2006. Pp. 179-190.

\section{References}

Andreev, V. K. (2012). City in nominations and texts (based on the material of the youth subcultures of Pskov), Vestnik Orl. gos. un-ta. Ser.: Novye gumanit. Issled, Orel, 2 (22), 125-128. (In Russian)

Boldyrev, N. N. (2020). A cognitive approach in linguistics and related fields of knowledge, Voprosy kognitivnoj lingvistiki, 2, 5-25. (In Russian)
Budaev, Je. V. and Chudinov, A. P. (2020). Political metaphorology at the present stage of development (2010-2019), Voprosy kognitivnoj lingvistiki, 3, 56-70. (In Russian)

Buteev, D. V. (2012). Pod pokrovom imjon: slovar' neofitsial'nyh toponimov g. Smolenska [Under the cover of Names: dictionary of unofficial toponyms of Smolensk], Madzhenta, Smolensk, Russia. (In Russian)

Vajrah, Ju. V. (2019). Ergourbonimija goroda Irkutska: strukturno-semanticheskij $i$ lingvokul'turologicheskij aspekty issledovanija [Ergourbonymy of the city of Irkutsk: structuralsemantic and linguoculturological aspects of the study], INFRA-M, Moscow, Russia. (In Russian)

Voronina, N. I. (2008). Goroda i ljudi: kul'turnaja identichnost': monografija [Cities and people: Cultural Identity: a monograph], Saransk, Russia. (In Russian)

Gorlanova, I. B. (2006).Toponymy of Kostroma, Abstract of Ph.D. dissertation, Yaroslavl, Russia. (In Russian)

Gribanova, L. V. and Gariko, O. S. (2011). Diachronic and synchronic aspects of Bryansk street nominations, Problemy vzaimodejstvija slavjanskih jazykov $i$ kul'tur $v$ ih istorii $i$ sovremennom sostojanii, Brjansk, 86-95. (In Russian)

Elistratov, B. C. (1994). Slovar' moskovskogo argo [Dictionary of Moscow Argo], Russkie slovari, Moscow, Russia. (In Russian)

Ermakova, O. P. (2011). Zhizn' rossijskogo goroda v leksike 30-40-h godov XX veka: Kratkij tolkovyj slovar' ushedshih $i$ uhodjashhih slov $i$ znachenij [The Life of the Russian City in the Vocabulary of the 30-40s of the XX Century: A Short Explanatory Dictionary of Past and outgoing words and meanings], Flinta Nauka, Moscow, Russia. (In Russian)

Erofeeva, T. I. (2017). Rechevoj portret provintsial'nogo goroda [Speech portrait of a provincial city], Flinta, Moscow, Russia. (In Russian)

Interpretatsija mira $v$ jazyke: kollektivnaja monografija [Interpretation of the world in language: a collective monograph] (2017), Tambov, Russia. (In Russian)

Iskuzhina, N. G. and Salikhova, Je. A. (2013). Heterogeneous language space of the city: the specifics of speech contact, Filologicheskie nauki: Voprosy teorii i praktiki, 3, 181-186. (In Russian)

Ismagilova, N. V. (2009). Jazyk goroda Ufy: funktsionirovanie razlichnyh podsistem russkogo jazyka $v$ uslovijah dvu- $i$ mnogojazychija 
[The language of Ufa: the functioning of various subsystems of the Russian language in the context of bilingualism and multilingualism], Han, Ufa, Russia. (In Russian)

Ismagilova, N. V. and Majorova, O. A. (2019). The language of the city as a sociolinguistic problem: perspectives of study, Vestnik Bashkirskogo un-ta, 4, 24, 900-909. (In Russian)

Ishakova, Z. A. (2001). Dvujazychie v gorodah Tatarstana (80-90-e gg.) [Bilingualism in the cities of Tatarstan (80-90s.)], Fiker, Kazan, Russia. (In Russian)

Rezanova, Z.I., Ermolenkina, L.I., Kostjashina, E.A., Katunin, D.A. and Mishankina, N.A. (2011). Kartiny russkogo mira: sovremennyj mediadiskurs [Pictures of the Russian World: a Modern Media Discourse], ID SK-S, Tomsk, Russia. (In Russian)

Kitajgorodskaja, M. V. and Rozanova, N. N. (2010). Jazykovoe sushhestvovanie sovremennogo gorozhanina: na materiale jazyka Moskvy [Linguistic existence of a modern citizen: on the material of the language of Moscow], Jazyki slavjanskih kul'tur, Moscow, Russia. (In Russian)Kolesov, V. V. (2005). Jazyk goroda [City language], Editorial URSS, Moscow, Russia. (In Russian)

Koptseva, N. P. and Sertakova, E. A. (2015). Sotsiokul'turnoe prostranstvo sovremennogo rossijskogo goroda (na materiale analiza goroda Krasnojarska): monografija [Sociocultural space of the modern Russian city (based on the analysis of the city of Krasnoyarsk): monograph], SFU, Krasnojar, Russia. (In Russian)

Korableva, G. V. and Merenkova, A. V. (2017). Sotsial'noe prostranstvo sovremennogo goroda: monografija [Social space of the modern city: monograph], Flinta, izd-vo Ural. un-ta, Moscow, Russia. (In Russian)

Krasil'nikova, E. V. (1990). Various phenomena in the language of residents of different cities, Functioning of the literary language in the Ural city, izd.-vo UrGU, Sverdlovsk, Russia, 412. (In Russian)

Krysin, L. P. (2003). The problem of social and functional differentiation in modern linguistics, Modern Russian language: social and functional differentiation, Moscow, Russia. (In Russian)

Kushneruk, S. L. (2018). Development of Cognitive-discourse world-modelling theory abroad and in Russia, Voprosy kognitivnoj lingvistiki, $4, \quad 115-125, \quad$ available at: www.discourseworld.ru (Accessed 25 December 2020). (In Russian)

Larin, B. A. (1977). The linguistic study of the city, History of the Russian language and General linguistics, Moscow, 175-189. (In Russian)

Mikhajlova, Ju. (2019). Media discourse of the modern city as a multicultural phenomenon, West-East, 2/2, 1, 93-96. (In Russian)

Ogneva, E. A. (2009). Kognitivnoe modelirovanie kontseptosfery khudozhestvennogo teksta [Cognitive modeling of the conceptual sphere of a literary text], Izd-vo BelGU, Belgorod, Russia. (In Russian)

Ogneva, E. A. (2019). Kontsepty-dominanty kak informativnye konstrukty tekstovyh mirov [Dominant concepts as informative constructs of text worlds], Moscow, Russia. (In Russian)

Podberezkina, L. Z. (1998). Linguistic urban studies, Theoretical and applied aspects of speech communication, 6. Krasnoyarsk Achinsk, Russia, 22-30. (In Russian)

Prokurovskaja, N. A. (1996). Gorod v zerkale svoego jazyka: na jazykovom materiale g. Izhevska [The city in the mirror of its language: on the linguistic material of Izhevsk], izd-vo Udm. gos. un- ta, Izhevsk, Russia. (In Russian)

Sovremennye gorodskie issledovanija: monografija [Modern Urban Studies: a monograph] (2020), in Savchenko, I. A., Kozlova, Ju. V. (eds.), INFRA-M, Moscow, Russia. (In Russian)

Stolbov, V. P. (2019). Sotsiologija gorodskoj sredy: monografija [Sociology of the Urban environment: a monograph], in Stolbov, V. P., Starosta, P. Ju., INFRA-M, Moscow, Russia. (In Russian)

Himik, V. V. (2000). Pojetika nizkogo, ili Prostorechie kak kul'turnyj fenomen [Poetics of the Low, or Colloquialism as a Cultural Phenomenon], izd-vo $\mathrm{SPb}$, Saint Petersburg, Russia. (In Russian)

Shkatova, L. A. (1988). The specifics of urban communication, Zhivaja rech' ural'skogo goroda, Sverdlovsk, 19-28. (In Russian)

Jemer, Ju. A. (2014). Spatial model of the city in folklore: on the problem of collective selfidentification of the citizen, Vestnik Tomskogo gos. un-ta, 1 (13), 18-24. (In Russian)

Junakovskaja, A. A. (2011). "The language of the city" as a linguistic problem, Vestnik Omskogo un-ta, 3, 193-197. (In Russian) 
Boydstun, A. E., Card D., Gross J. H., Resnik P. and Smith N. A. (2014). Tracking the development of media frames within and across policy issues, Working Paper, 1-25. (In English)

Brüggemann, M. (2014). Between frame setting and frame sending: How journalists contribute to news frames, Communication Theory, 24 (1), 61-82. (In English)

Cacciatore, M., Scheufele, D. and Iyengar, S. (2016). The End of Framing as We Know It ... and the Future of Media Effects, Mass Communication and Society, 19 (1), 7-23. (In English)

D'Angelo, P. (2010). Introduction: Doing News Framing Analysis, in D'Angelo, P. and Kuypers, J., Doing News Framing Analysis: Empirical and Theoretical Perspective, Routledge, New York, USA, 1-14. (In English)

De Vreese, C. (2005). News framing: Theory and typology, Information Design Journal, 13 (1), 51-62. (In English)

Entman, R. M. and Framing, U.S. (1991). Coverage of international news: Contrasts in narratives of the KAL and Iran air incidents, Journal of Communication, 41(4), 6-27. (In English)

Entman, R. M. (1993). Framing: Toward clarification of a fractured paradigm, Journal of Communication, 43(4), 51-58. (In English)

Gamson, W. A. and Modigliani, A. (1987). The Changing Culture of Affirmative Action, Research in Political Sociology, 3, Jai Press, Inc, Greenwich, 37-177. (In English)

Godefroidt, A., Berbers, A. and d'Haenens, L. (2016). What's in a frame? A comparative content analysis of American, British, French, and Russian news articles, The International Communication Gazette, 78 (8), 777-801. (In English)

He, M. (2010). An analysis of framing in British news media representations of China and the Chinese, Ph.D. Thesis, Loughborough University, available at: https://dspace.lboro.ac.uk/dspace-

jspui/bitstream/2134/8470/2/Miao's $\mathrm{PhD}$ thesis for binding.pdf (Accessed 25 December 2020). (In English)

Ireri, K., Chege, N., Kibarabara, J. and Onyalla Don Bosco (2019). Frame Analysis: Newspaper Coverage of Kenya's Oil Exploration in the Post-2012 Discovery Era, African Journalism Studies, 40(2), 34-50. (In English)

World Building: Discourse in the Mind (2016). In Gavins, J., Lahey, E. (eds). Bloomsbury. (In English)
Kerbo, H. R. and Coleman J. W. (2006). Social Problems, Social Sciences, 362-369. (In English)

Matusitz, J. (2013). Terrorism and Communication: A Critical Introduction, Sage, London. (In English)

Reese, S. D. (2007). The framing project: A bridging model for media research revisited, Journal of Communication, 57(1), 148-154. (In English)

Tewksbury, D. H. and Scheufele, D. A. (2009). News Framing Theory and Research, in Jennings Bryant \& Oliver Mary Beth (eds.), Media Effects: Advances in Theory and Research, Erlbaum, Hillsdale, 17-33. (In English)

Tuchman, G. (1987). Making news, Free Press, New York, USA. (In English)

Van Dijk, T. (2016). Sociocognitive Discourse Studies, in Richardson J., Flowerdew J. (eds), Handbook of Discourse Analysis, Routledge, available at: http://www.discourses.org/OldArticles/Sociocogn itive\%20Discourse\%20Studies.pdf_(Accessed 25 December 2020). (In English)

Van Gorp, B. (2005). Where is the frame? Victims and Intruders in the Belgian press coverage of the asylum issue, European Journal of Communication, 20 (4), 484-507. (In English)

Wodak, R. (2006). Mediation between discourse and society: assessing cognitive approaches in CDA, Discourse Studies, 8 (1), 179-190. (In English)

\section{Конфликты интересов: у автора нет конфликта интересов для декларации. \\ Conflicts of Interest: the author has no conflict of interest to declare.}

Кушнерук Светлана Леонидовна, профессор кафедры теории и практики английского языка Челябинского государственного университета, профессор кафедры английской филологии Южно-Уральского государственного гуманитарно-педагогического университета, доктор филологических наук, доцент.

Kushneruk Svetlana Leonidovna, Professor of Theory and Practice of the English Language Department, Chelyabinsk State University; Professor of English Philology Department, South Ural State Humanitarian and Pedagogical University; Doctor of Philology, Associate Professor. 